\title{
The management of traumatic tooth loss with dental implants: Part 1
}

\author{
J. Chesterman, ${ }^{* 1}$ R. Chauhan, ${ }^{2}$ M. Patel ${ }^{3}$ and M. F. W.-Y. Chan ${ }^{4}$
}
IN BRIEF
- Discusses the management of a traumatised tooth with a hopeless prognosis, in order to preserve the supporting hard and soft tissues and facilitate predictable implant placement.
- Describes the considerations for replacing a single tooth lost due to trauma with a dental implant.
- Shows methods for the augmentation of the alveolar ridge in a single tooth defect where supporting hard tissues are lost.

Traumatic dental injuries are relatively common causes of emergency presentation to general dental practitioners. There are well established guidelines for the management of traumatised teeth, which practitioners should be familiar with and able to deliver. Some teeth, however, are either lost at the time of injury or are found to have a hopeless long-term prognosis despite appropriate treatment. The first article in this two-part series covers the important aspects of maintaining teeth where possible, to preserve the supporting hard and soft tissues. It then describes the replacement of a single tooth lost due to trauma and the relative challenges faced. The second article covers more extensive trauma, involving multiple teeth and where significant supporting tissues are lost. It describes the replacement of teeth, including the hard and soft tissues with implant supported restorations, whilst highlighting the need for a multidisciplinary team in severe cases.

\section{INTRODUCTION}

Dental trauma can be defined as an injury to the oral region including the lips, teeth, periodontal tissues, tongue and/or alveolar processes. ${ }^{1}$ The aims of management will depend on the age of the patient, type of tooth (primary or permanent) and the extent of the injuries. Three quarters of all traumatic injuries occur in childhood and adolescence. ${ }^{2}$ Between 6-34\% of children aged 8-15 suffer some form of dental trauma. ${ }^{3}$ Affected teeth often have a reduced prognosis and in some instances may require extraction. ${ }^{4}$ The majority of dental trauma is initially seen within a primary rather than secondary care setting. ${ }^{5}$ General dental practitioners should therefore be able to effectively manage the most common dental injuries. Clear guidelines for the management of traumatised teeth are available, ${ }^{6}$ which aim to prolong the natural dentition.

Unfortunately, despite best efforts, some traumatised teeth do have a poor prognosis. This can be apparent from the outset or after a variable time period. Complications such as

Speciality Dentist, Restorative Dentistry Department, Leeds Dental Institute, Clarendon Way, Leeds, LS2 9LU; ${ }^{2}$ Speciality Registrar, Restorative Dentistry, King's College Hospital, Denmark Hill, London, SE5 9RS; ${ }^{3}$ Consultant in Restorative Dentistry, Dental Institute, Barts Health NHS Trust, London, E1 1BB; ${ }^{4}$ Consultant in Restorative Dentistry, Leeds Dental Institute, Clarendon Way, Leeds, LS2 9LU

${ }^{*}$ Correspondence to: Mr James Chesterman Tel: +44 (0)79 4902 4649;

Email: james.chesterman@nhs.net

\section{Refereed Paper}

Accepted 5 September 2014

DOI: 10.1038/sj.bdj.2014.1050

${ }^{\circledR}$ British Dental Journal 2014; 217: 627-633 inflammatory resorption, replacement resorption or endodontic failure do occur in some cases. Therefore, it is important to consider suitable replacement options early, where teeth are considered to have a poor prognosis.

\section{OPTIONS FOR TOOTH REPLACEMENT}

When a single tooth is lost or extracted due to trauma the following options are considered:

- Leaving the space - usually unacceptable for an anterior tooth due to appearance and can lead to drifting/tipping of adjacent teeth and overeruption of opposing teeth. There may be difficulties replacing the tooth later due to space loss

- Dental implant supported crown - see below

- A removable prosthesis - often used as an immediate tooth replacement and for space maintenance. However, this may be considered as a long term option in some cases with appropriate hygienic denture design

- Conventional fixed bridge - useful where there are adjacent crowned/ heavily restored teeth. Not indicated in young patients with an otherwise healthy dentition

- Adhesive fixed bridge - reversible and conservative option, with favourable success rates using appropriate techniques. ${ }^{7}$ Adhesive fixed bridges can also be used as a medium term option in patients too young for implant placement

- Autotransplantation - in carefully planned cases this can be a successful option, which can be performed in children, unlike dental implants. ${ }^{8}$ If the periodontal ligament health is maintained, the transplanted tooth will erupt with the other teeth, can be moved orthodontically and may have improved aesthetics of the dental papillae ${ }^{8}$

- Orthodontic space closure - often useful if there is crowding elsewhere. It is important to involve an orthodontist in the planning of these cases to achieve optimal results.

The remainder of this article will discuss the various considerations for an implant restoration to replace an unrestorable or lost single tooth.

\section{PLANNING FOR TOOTH LOSS AND PROVISION OF AN IMPLANT SUPPORTED RESTORATION}

\section{Assessment}

An initial assessment should begin with a thorough history and clinical examination. Firstly, the patient's medical, dental and social histories must be considered as they may influence whether future implant treatment is a predictable treatment option for the patient.

Many of the risk factors to implant provision can be overcome, although multiple risk factors should alert the clinician to the possibility of failure. ${ }^{9}$ The patient must be aware of these risk factors and how they impact upon their treatment. All the alternative options should be considered and discussed with the 


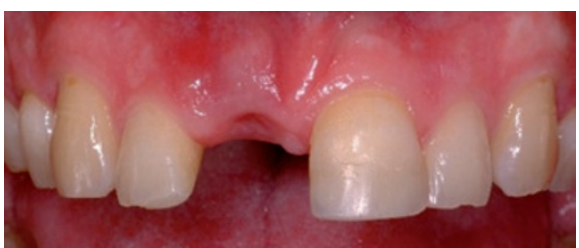

Fig. 1a Trauma to the 11 resulted in an unrestorable coronal fracture

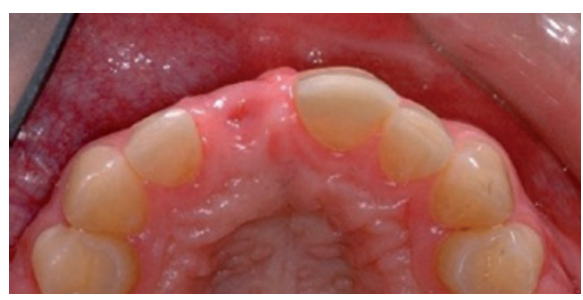

Fig. 1b The presence of an infection free root/tooth can maintain the labial bony profile and the supporting soft tissues

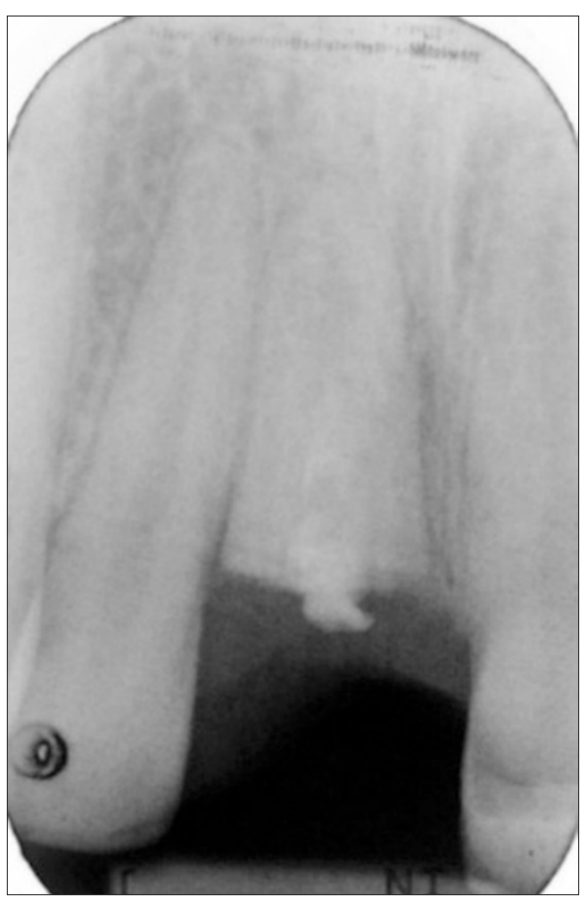

Fig. 1c Radiograph of 11 retained root

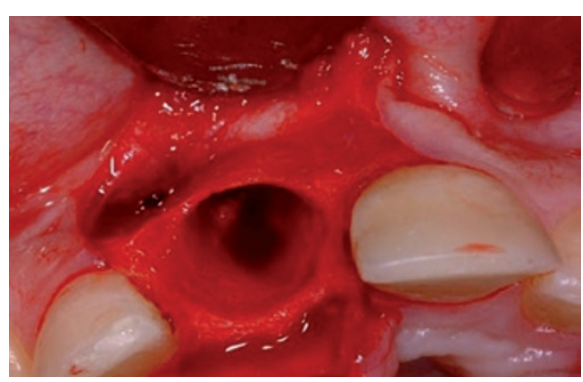

Fig. 1d Flap reflection, atraumatic removal of the retained root and preparation of the pilot osteotomy site, in the bone palatal and apical to the root

patient in order to gain proper informed consent. This should include information on the longevity of restorations, need for maintenance and potential replacement treatments, especially for young adult patients.

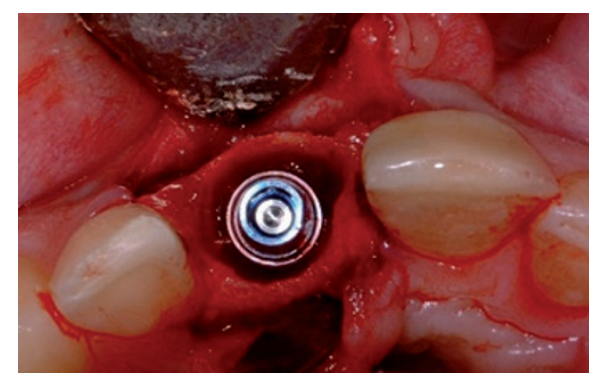

Fig. 1e Implant placement is to the palatal aspect of the socket to protect the labial bone and facilitate a screw retained restoration

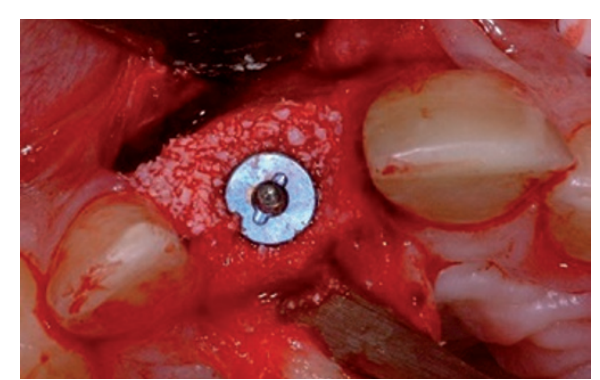

Fig. $1 f$ The space between the extraction socket wall and the implant is augmented with particulate xenograft (Geistlich Bio-oss ${ }^{\circ}$ )

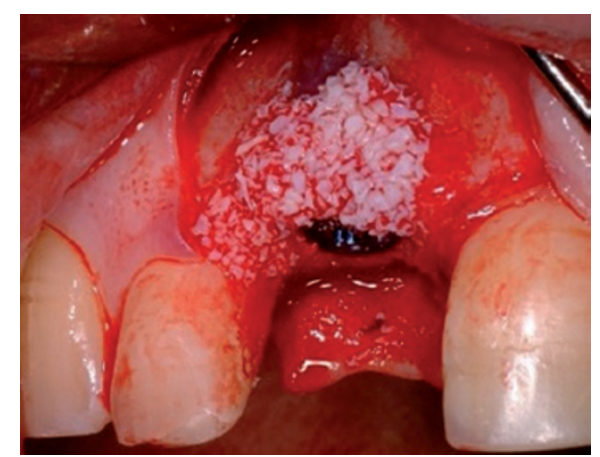

Fig. $1 \mathrm{~g}$ The labial aspect is also augmented with particulate xenograft to minimise resorption of the labial bone plate

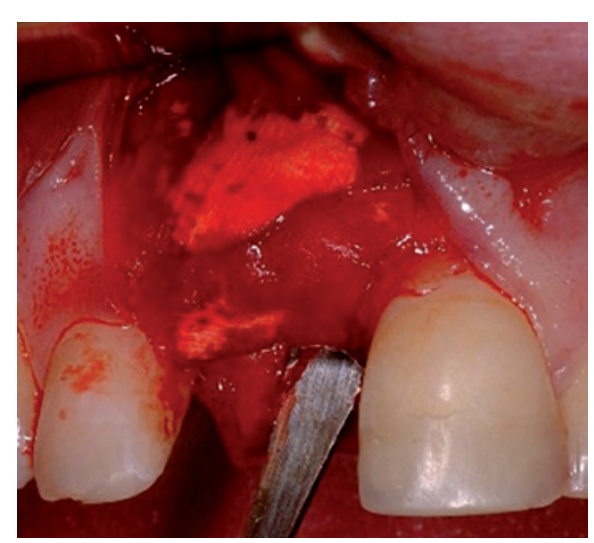

Fig. $1 \mathrm{~h}$ A resorbable collagen membrane (double layer) is placed over the particulate xenograft

\section{Maintaining teeth and roots with a poor prognosis}

Avulsion of teeth, severe intrusion and horizontal root fractures may result in a reduced long term prognosis. ${ }^{6}$ However,

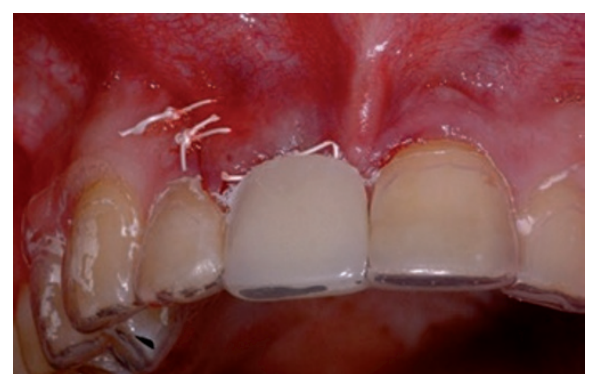

Fig. 1i A vacuum formed splint denture is a useful immediate replacement, which can be easily relieved from the mucosa

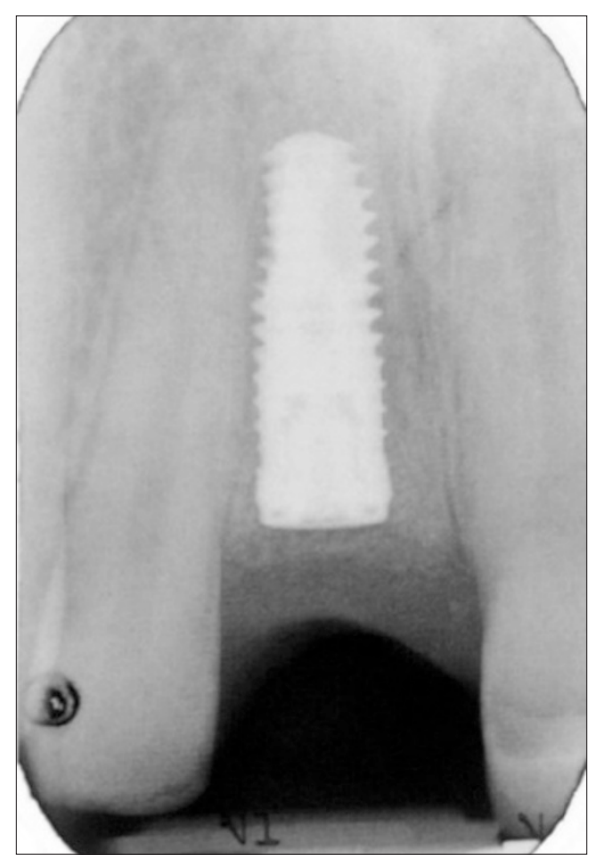

Fig. 1j Implant has been placed and submerged for a period of healing

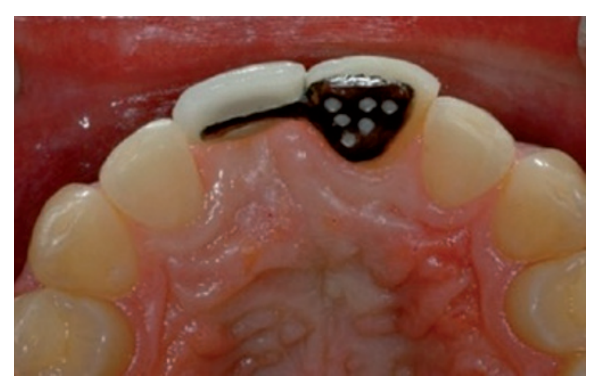

Fig. 1k A Rochette bridge provides good medium term space maintenance and aesthetics. Restored by Mr R. Ali

traumatised teeth can provide useful function and maintain aesthetics in the interim even if extraction is planned in the future. In young patients, their retention in the absence of infection, may allow the normal development of the alveolar processes to continue, which could be adversely affected by early tooth loss. They also can help preserve the tooth/pontic space, occlusal relationship and volume of alveolar bone/soft tissues for subsequent implant treatment.

Implant provision is generally delayed until growth cessation, which is typically at 


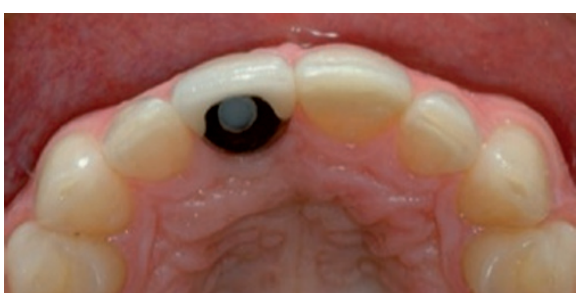

Fig. 11 Retrievable screw retained restoration 11 is possible due to the correct implant positioning. The labial profile of the hard and soft tissues has been maintained post extraction

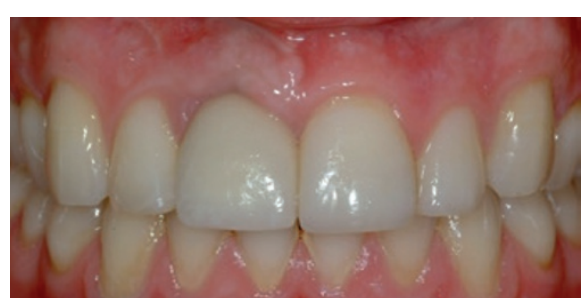

Fig. $1 \mathrm{~m}$ Completed implant crown and minor composite bonding of adjacent teeth

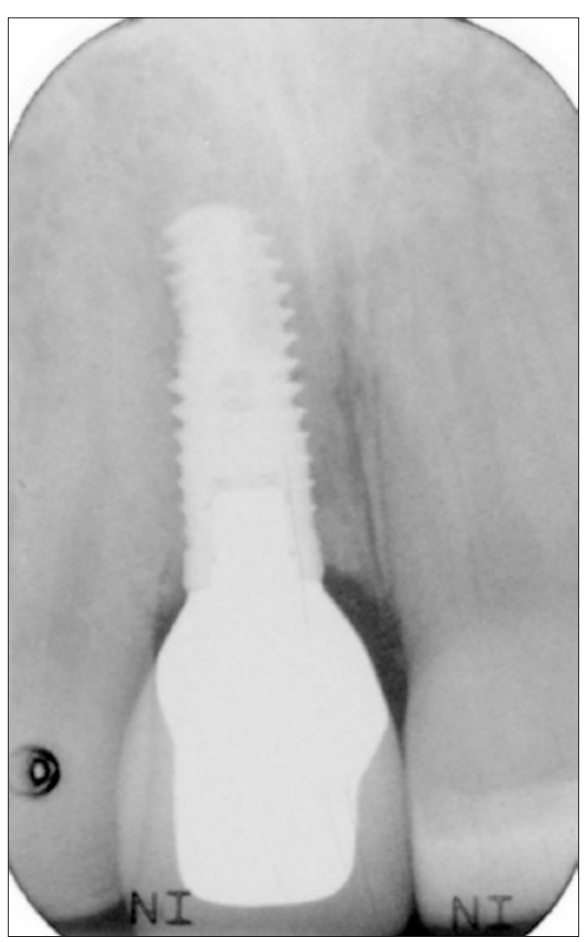

Fig. 1n Radiograph of implant crown 11 after 2 years, demonstrating good bone levels

eighteen years, but patients may continue to grow into the early third decade. ${ }^{10}$ In younger patients where alveolar development is incomplete, root retention and possible surgical covering with a mucoperiosteal flap has been advocated. ${ }^{11}$ Roots retained in this way preserve alveolar bone and allow its further development, with few reported complications. ${ }^{11}$ This can be considered in horizontal root fracture ${ }^{10}$ or in severely intruded teeth, ${ }^{12,13}$ that cannot be surgically or orthodontically positioned into occlusion. In the latter case the intruded tooth can be decoronated and the root left in situ.
Orthodontic extrusion of hopeless teeth and retained roots to a more supra-gingival position can improve the hard/soft tissue level and create a better site for subsequent implant placement. ${ }^{14}$

It is also important to consider the prognosis of adjacent teeth that may have been traumatised. The replacement of a single tooth with an implant supported restoration may be complicated or compromised by the loss of adjacent teeth mid-treatment. Therefore, adjacent teeth with poor prognosis should be considered for extraction at an earlier stage of treatment.

\section{Failing endodontic treatment}

Periradicular infection can result in significant bone resorption and can make subsequent implant treatment more difficult. A clinical decision on whether to keep a tooth must be based upon the potential risk of causing more bony destruction due to infection; what bone may be maintained by keeping the tooth; and the relative chance of success of further endodontic treatment. If apical surgery or re-root canal treatment has a poor prognosis and the risk of further bone loss is significant, early extraction is often indicated.

\section{Unfavourable tooth positioning}

Unfavourable tooth position may have occurred due to traumatic displacement of the teeth and their supporting tissues at time of injury or as a result of drifting, due to inadequate space maintenance. This stresses the importance of space maintenance if teeth or clinical crown height are lost.

Treatment planning with articulated study models will be required in order to assess the clinical situation fully. Malpositioned teeth can sometimes be recontoured or masked though composite bonding, veneers or crowns. They may also be realigned with orthodontic treatment or be considered for elective extractions in severe cases. It is important to gain an orthodontic opinion in cases of significant malpositioning. In addition, the tooth angulation and root position should be assessed, as it may impact on space available for implant placement.

A minimum space of 6-7 $\mathrm{mm}$ is required between adjacent teeth and roots, with at least $1 \mathrm{~mm}$ of surrounding bone in all directions around an implant. Therefore, space may need to be maintained to prevent drifting and tilting of adjacent teeth. In some cases space may need to be corrected with orthodontic treatment. In the younger patient, clinicians may wish to use the space to relieve a crowded dentition after careful orthodontic assessment and then eliminate the need for a prosthetic replacement.

\section{Ridge preservation techniques and space maintenance}

If a tooth requires extraction, clinicians must aim to achieve an atraumatic extraction to minimise the loss of the labial or marginal bone. When extractions are indicated clinicians may also utilise ridge preservation techniques to preserve alveolar bone and facilitate later implant placement. A recent review ${ }^{15}$ identified nine different techniques for ridge preservation and showed no technique to be more effective than another. ${ }^{15}$ It also concluded that ridge preservation may not always facilitate later implant placement. ${ }^{15}$ The three most commonly used methods identified in this review were:

1. Grafting of the extraction socket followed by coverage with a membrane and soft tissue closure

2. Grafting of the extraction socket followed by soft tissue closure alone

3. Coverage of the extraction socket with a membrane followed by partial or complete soft tissue closure.

The treatment of extraction sites with either non-resorbable or resorbable barrier membranes may lead to less ridge resorption and the preservation of sites for later implant placement. ${ }^{15}$ However, in failing to achieve good soft tissue coverage with subsequent exposure of these membranes, the regenerative outcome can be compromised. ${ }^{15}$ If the membranes become exposed, fewer complications are associated with resorbable collagen membranes compared to e-PTFEE (expandedpolytetrafluoroethylene). ${ }^{15}$ If the membrane becomes exposed there is risk of infection. ${ }^{15}$ To minimise the risk of infection any exposure can be managed with meticulous oral hygiene and use of chlorhexidine $0.2 \%$ mouthwash.

Space may then be maintained by use of a removable appliance with a gum fitted prosthetic tooth, a resin bonded bridge or using the natural tooth crown bonded to adjacent teeth.

\section{PROVISION OF AN IMPLANT SUPPORTED RESTORATION}

\section{Alveolar ridge}

Clinicians faced with loss of a single tooth with an intact alveolus and favourable soft tissues have a choice when it comes to the timing of implant placement. In providing an implant replacement there are three main options:

\section{A. Extraction and immediate placement}

Clinicians may choose to place an implant immediately into a fresh extraction socket (Figs 1a-n). Success has been reported in the literature with such techniques. ${ }^{16}$ However, a recent review ${ }^{17}$ concluded that 


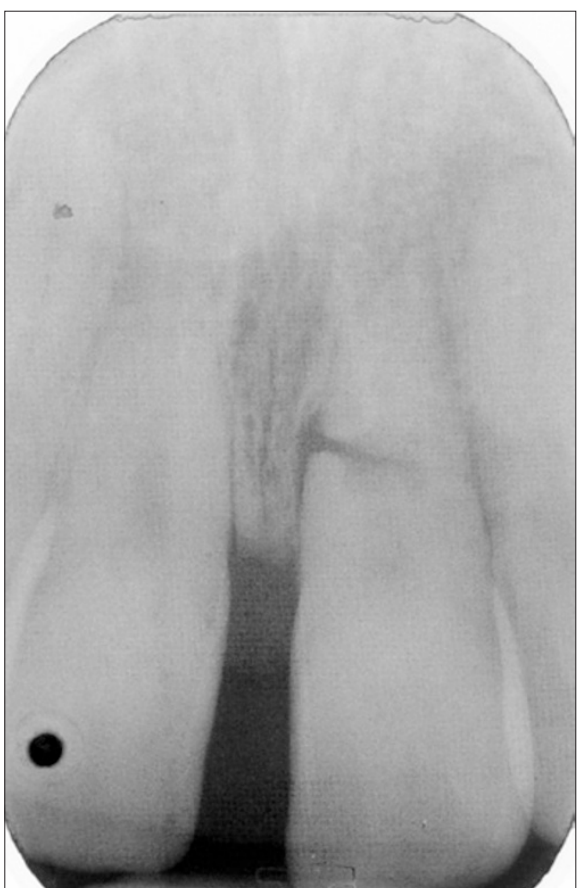

Fig. 2a A middle third root fracture of the 21 associated with internal root resorption

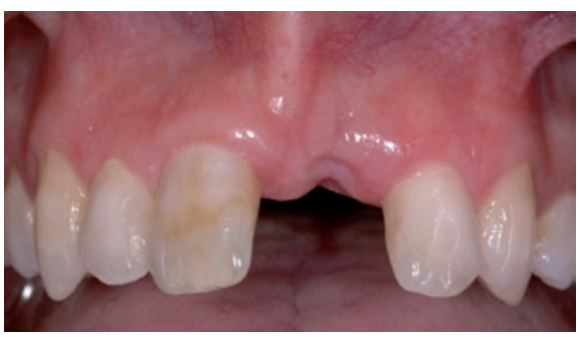

Fig. $2 \mathrm{~b}$ The 21 was extracted, 8 weeks later a "delayed-immediate" implant was planned

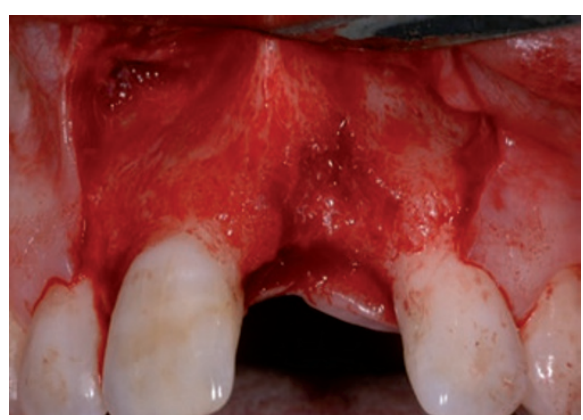

Fig. 2c 21 extraction site with labial deficiency of the alveolar bone

there is insufficient evidence to show any advantages of placing implants into fresh extraction sockets over delayed placement. The aesthetic outcome may benefit from immediate placement, however, it may have a higher overall failure rate. ${ }^{17}$ It also carries a higher risk of infection and poor primary implant stability. The following criteria are recommended before placing implants into fresh extraction sockets: ${ }^{18}$

- Absence of purulent discharge or active periapical pathology

- Healthy periodontal tissues with a good soft tissue profile to optimise aesthetics

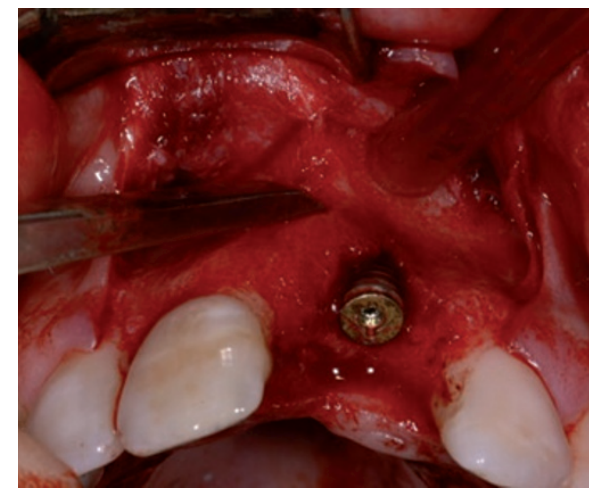

Fig. 2d Implant placed with labial bony dehiscence. Bone chips being harvested from the local area using a hand chisel

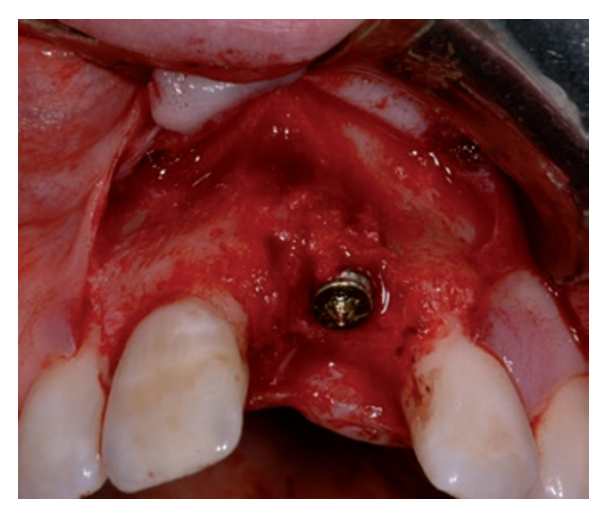

Fig. 2e Bone chips placed over the implant surface

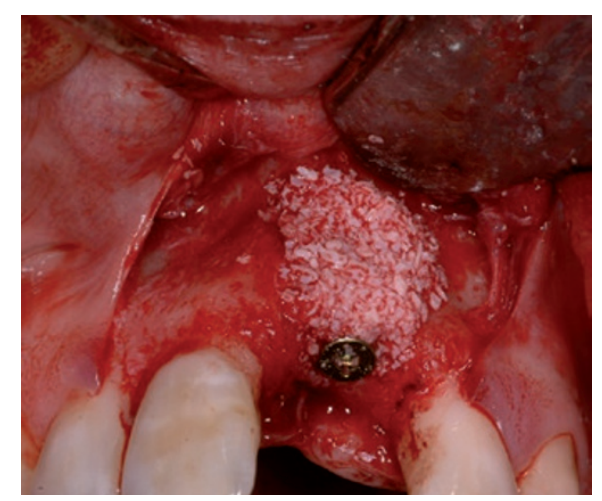

Fig. 2f Particulate xenograft placed as a second layer to bulk out the alveolar ridge

- A healthy adult patient without a history of poor wound healing (for example, poorly controlled diabetes)

- The presence of good quality and adequate volume of bone.

It has been shown that immediately placed implants can successfully osseointegrate without the need for bone grafting procedures. ${ }^{19}$ One randomised control study showed that an implant will successfully osseointegrate if the gap between the implant and bony wall is less than $2 \mathrm{~mm} .{ }^{20}$ Bone will, however, continue to remodel externally with up to $56 \%$ being reported to be resorbed buccally and 30\% palatally. ${ }^{21}$ Another issue is the fact there may be a lack of soft tissue to cover the implant

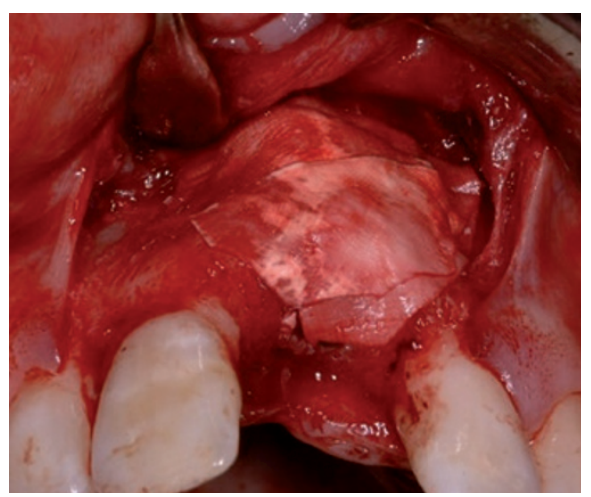

Fig. $2 \mathrm{~g}$ A resorbable collagen membrane (double layer) is placed over the graft

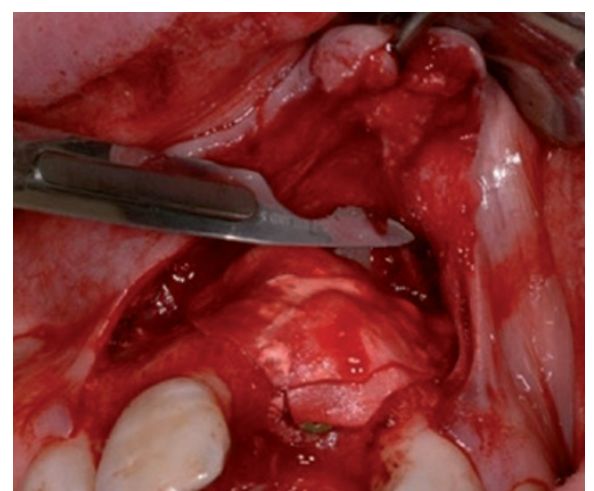

Fig. $2 \mathrm{~h}$ Periosteal release is made to mobilise the flap

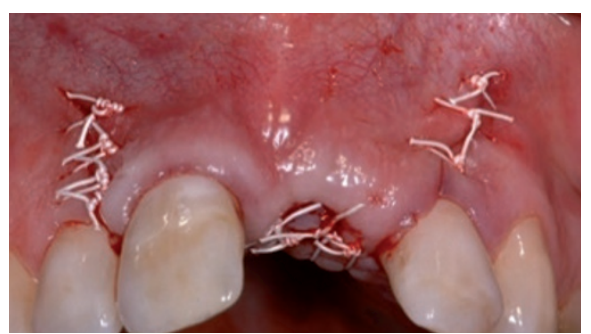

Fig. $2 \mathrm{i}$ Tension free closure to minimise the risk of dehiscence

necessitating a further surgical procedure and the increased chance of failure if the socket becomes infected..$^{22}$ Some authors have also suggested that tissue recession is unpredictable with immediate implants and there is also often a problem with temporisation..$^{23}$

\section{B. Extraction and early implant placement (6-8 weeks)}

Also known as 'delayed-immediate' implants, clinicians may choose to place implants following a period of soft tissue healing which will facilitate flap closure and allow previous infections to heal (Figs 2a-k). ${ }^{24}$ It may also allow the early healing of the extraction socket without excessive resorption of the buccal plate.

\section{Extraction and late placement (approximately 3 months)}

These are also known as ‘delayed' implants and will allow for more bone and soft tissue 


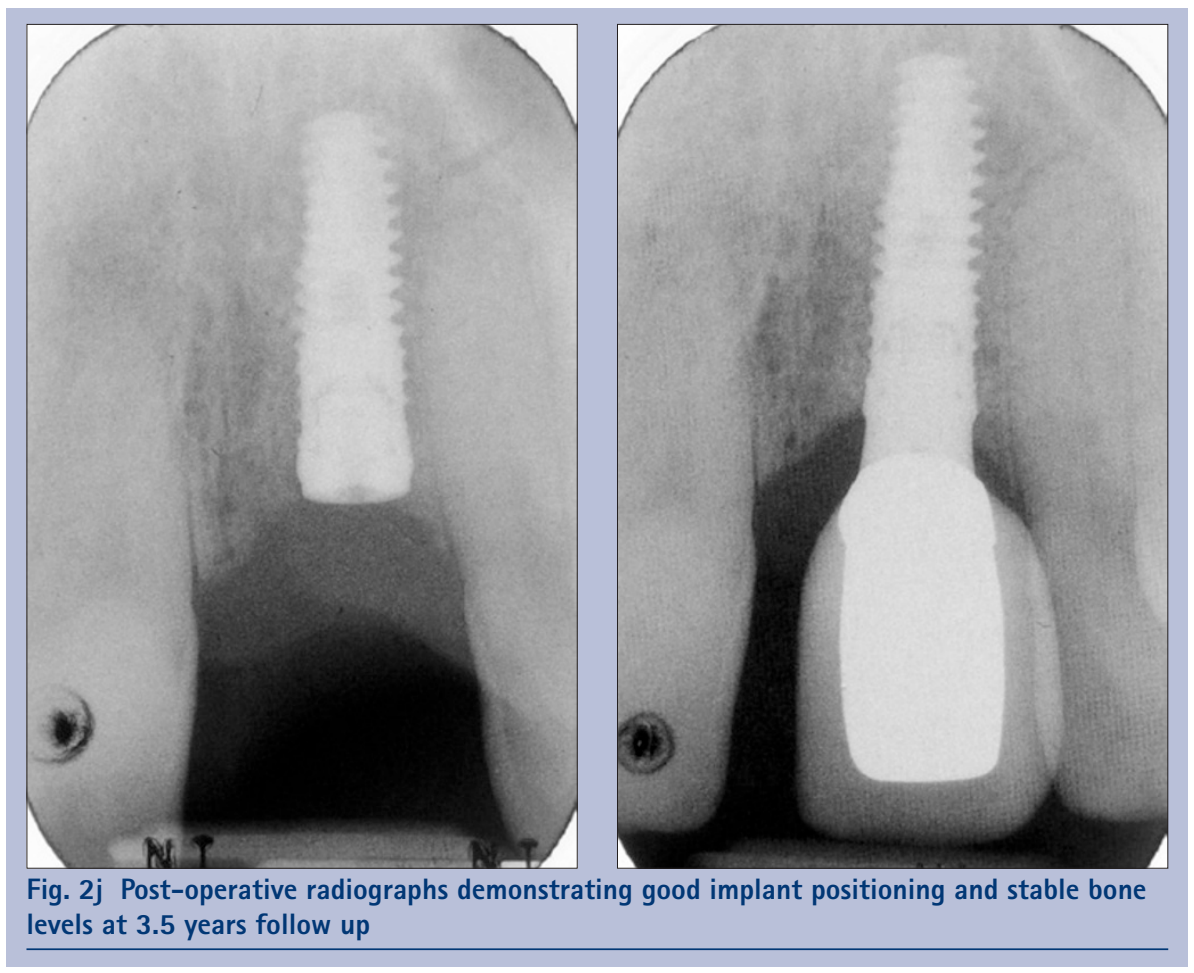

healing which will facilitate flap closure, allow previous infections to heal, ${ }^{24}$ and offer a greater degree of primary implant stability. This option is usually used in the following situations: $:^{25}$

- Extremely thin surrounding bone

- Close proximity to adjacent vital structures

- A socket that is significantly larger in diameter than the proposed implant

- A lack of bone beyond the apex of the tooth to be extracted

- Active apical infection at the time of extraction.

Extraction sockets may require grafting in the above situations to augment the remaining bone, promote healing and attempt to counteract the normal physiological process of bone resorption. In cases where traumatic or surgical extraction has led to the loss of labial bone or there is a significant vertical defect, more complex grafting procedures may be required as described below.

\section{Deficient alveolar ridge}

A thorough assessment of the site and a diagnosis of the alveolar defect will be required before the placement of an implant.

\section{Ridge volume}

The loss or extraction of a tooth will result in variable alveolar ridge resorption both vertically and horizontally. Assessment of the bone is initially made by visual inspection and tactile palpation. Traditionally, ridge mapping was carried out where a calibrated probe is pushed through the anaesthetised soft tissues and measurements transferred to a sectioned cast of the ridge. However, this has been superseded by cone-beam computed tomography (CBCT). CBCT imaging is indicated when there is doubt about the shape of the alveolar ridge or the proximity of important anatomical structures to the planned implant site, that is, maxillary sinus, nasal floor, nasopalatine canal, mental foramen or the inferior dental nerve. ${ }^{26}$ A diagnostic wax up is usually constructed to determine and trial the ideal prosthetic tooth positioning. Once this has be confirmed clinically, a radiographic guide can be constructed matching the diagnostic wax-up to assess the relationship of the alveolar to the ideal tooth position, which can later be used as a surgical guide to aid correct implant placement. Classification of the alveolar ridge may be useful in aiding the planning process and there are several classifications available, which are beyond the scope of this article. The options for augmenting an alveolar ridge defect are as follows:

Autogeous bone graft: In cases where small quantities of autogenous bone are required this can be harvested locally. For instance, when performing the osteotomy for implant placement, a bone trap may be used $^{27}$ or by using a bone scraper around the implant site. This autogenous bone is often mixed with other sources of bone grafting material.

Larger alveolar defects can be augmented with autogenous block grafts, which traditionally have been deemed the gold standard. Typically bone can be harvested from

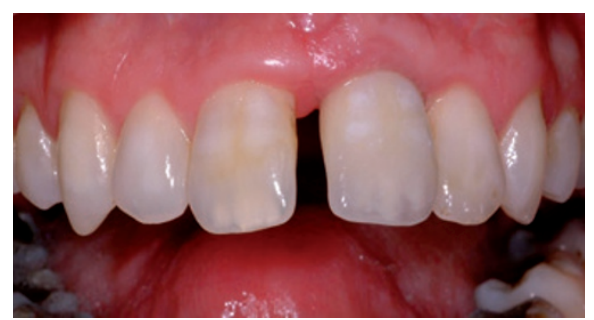

Fig. 2k The final implant crown 21 reproducing the diastema and matching the natural adjacent tooth. Restored by Mr P. Nixon

intra-oral sites such as the mandibular symphasis or ramus, which is suitable for moderate defects. ${ }^{28}$ However, up to $33 \%$ of patients may suffer post-operative morbidity. ${ }^{29}$ Complications are reported to be post-operative pain, paraesthesia of the lip/ chin, dehiscence of the recipient site, superficial infection and an altered chin profile. ${ }^{29}$ Others report that the technique can be used very successfully, with relatively few complications. ${ }^{30}$

Intra-oral autogenous block grafts often provide a sufficient amount of bone to graft one or two tooth defects. However, where larger defects exist and more substantial bone is required, extra-oral grafts are considered such as the iliac crest site. ${ }^{28}$

Guided bone regeneration and bone substitutes: The use of xenograft, allograft or synthetic grafting materials may be used alone or combined with autogenous particulate bone. They are particularly useful where there is a labial/buccal deficiency or concavity requiring augmentation at the same time as implant placement (Figs $1 \mathrm{~g}$ and 2f). The grafts are typically placed with a resorbable or non-resorbable membrane which has shown to increase the volume of augmented bone (Figs $1 \mathrm{~h}$ and $2 \mathrm{~g}$ ). ${ }^{31}$ There is no evidence to support one type of membrane over the other. ${ }^{31}$ A resorbable membrane prevents the need for an additional surgical procedure, which contributes to scaring of the soft tissues. This is often all that is required in the case of a single tooth defect. ${ }^{32}$ However, with inherently more difficult vertical augmentation the predictability of these techniques is reduced. ${ }^{31}$

\section{Soft tissues}

The appropriate management of soft tissues is essential for a good aesthetic outcome. The appearance of the overlying soft tissues will also be governed by the following factors:

- Presence of an adjacent natural tooth and its interproximal bone level. An interdental papilla is more likely to be present if the distance between the interproximal contact point and the crest of the bone is $3-4 \mathrm{~mm}$ or less. ${ }^{33} \mathrm{~A}$ slightly over-contoured implant retained provisional restoration is often used 
to shape the soft tissues and create the illusion of an interdental papilla (Figs 3a and b)

- Periodontal biotype: patients with a thick periodontal biotype may be more resistant to recession ${ }^{23}$

- Number of surgical interventions: clinicians should aim to minimise the number of interventions and make incisions along previous incision lines if repeated interventions are needed to minimise the formation of scar tissue

- Position of the implant:

-The buccal-palatal position affects the soft tissue level, as implants placed too far labially will result in a soft tissue defect and the appearance of gingival recession

-The apical-coronal level of the implant will also affect the emergence profile and gingival margin labially. The implant shoulder should ideally be approximately $3 \mathrm{~mm}$ apical to the mid-labial gingival margin of the planned restoration. ${ }^{34}$

Soft tissue augmentation may be needed to improve the aesthetic outcome. This may include the use of connective tissue grafts, free gingival grafts and allografts to improve the volume and quality of soft tissues around implants. A lack of keratinised mucosa around implants may increase the risk of recession and make plaque control challenging for the patient. In turn, this may increase the risk of peri-implantitis around these implants. ${ }^{35}$

Small soft tissue defects can be masked with the use of pink porcelain or composite upon the implant crown. This requires careful shade matching and an experienced technician to achieve good results. Soft tissue defects are more common in severe trauma and options to manage this are covered in part 2.

\section{Other factors}

- Occlusion: A deep overbite and/or severe parafunctional habits have been suggested as relative contra-indication to implant placement. However, they also cause difficulties with tooth supported restorations and removable prosthesis. Where possible, guidance in excursive movements should be shared among natural teeth. In parafunctional patients, use of an appropriate night guard is recommended

- Smile line: This will broadly fall into two categories:

-High: Gingival margin discrepancies, interdental papillae, ridge shape and tooth size will be noticeable. Patients may have to accept an aesthetic
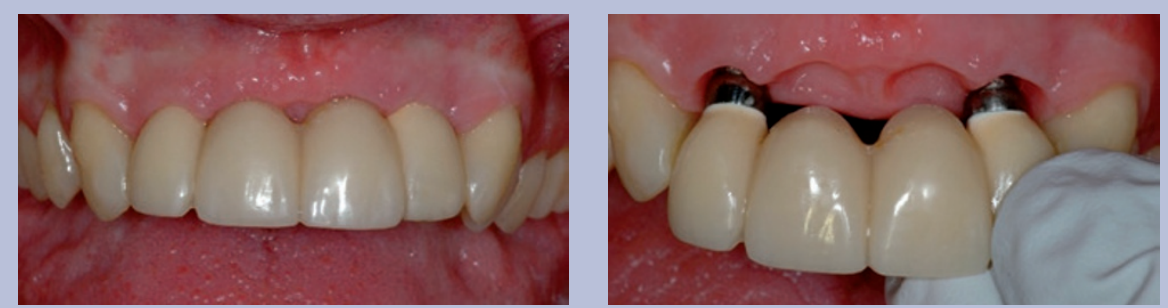

Figs $3 a$ and $b$ The use of a provisional restoration to condition the soft tissues and gain a good emergence profile with the illusion of interdental papillae. The use of ovate pontics to improve aesthetics

compromise and have realistic expectations in this situation -Low: Aesthetic discrepancies may be more acceptable in patients with a low smile line.

\section{CONCLUSION}

Despite treatment to preserve teeth affected by dental trauma some teeth will be lost early or have a hopeless prognosis. Careful assessment is needed to select the most appropriate treatment modality. An implant supported restoration is often the best choice in the adult patient. Although in the growing child it is often beneficial to prolong the life of a tooth in the absence of infection in order to allow normal development. It will also preserve existing bone and soft tissues until growth is complete. Careful clinical assessment, planning and contemporary imaging techniques are required to achieve optimal results. Appropriate timing of tooth extraction, the use of hard/soft tissue augmentation techniques and ideal implant positioning help to facilitate a good aesthetic and functional outcome of the definitive implant supported restoration.

The authors wish to thank Ms Louise Hughes, dental implant coordinator for photography support.

1. Glendor U, Marcenes W, Andreasen J O. Classification, epidemiology and etiology. In Andreasen J O, Adreasen F M, Andersson L (ed) Textbook and colour atlas of traumatic injuries to the teeth. 4th ed. pp 217-218. West Sussex: WileyBlackwell, 2007.

2. Petersson E E, Andersson L, Sorensen S. Traumatic oral vs non-oral injuries. Swed Dent J 1997; 21: 55-68.

3. Chadwick B L, White D A, Morris A J, Evans D, Pitts $\mathrm{N} B$ Non-carious tooth conditions in children in the UK, 2003. Br Dent J 2006; 200: 379-384.

4. Maguire A, Murray J J, Al-Majed I. A retrospective study of treatment provided in the primary and secondary care services for children attending a dental hospital following complicated crown fracture in the permanent dentition. In J Paediatric Dent 2000; 10: 182-190.

5. Al-Jundi S. Type of treatment, prognosis, and estimation of time spent to manage dental trauma in late presentation cases at a dental teaching hospital: a longitudinal and retrospective study. Dent Traumatol 2004; 20: 1-5.

6. International Association of Dental Traumatology. The dental trauma guide. Information available online at http://dentaltraumaguide.org/ (accessed 10 November 2014).

7. Durey K A, Nixon P J, Robinson S, Chan M F W-Y.
Resin bonded bridges: Techniques for success. Br Dent J 2011; 211: 113-118.

8. Amos M J, Day P, Littlewood S J. Autotransplantation of teeth: an overview. Dent Update 2009; 36: 102-113.

9. Palmer R M. Risk management in clinical practice. Part 9. Dental implants. Br Dent J 2010; 209: 499-506.

10. Oesterle L J, Cronin R J Jr. Adult growth, aging, and the single-tooth implant. Int J Oral Maxillofac Implants 2000; 15: 252-260.

11. Rodd H D, Davidson L E, Livesey S, Cooke M E. Survival of intentionally retained permanent incisor roots following crown root fractures in children. Dent Traumatol 2002; 18: 92-97.

12. Malmgren $B$, Cvek $M$, Lundberg $M$, Frykholm $A$. Surgical treatment of ankylosed and infrapositioned reimplanted incisors in adolescents. Scand J Dent Res 1984; 92: 391-399.

13. Filippi A, Pohl Y, Von Arx T. Decoronation of an ankylosed tooth for preservation of alveolar bone before implant placement. Dent Traumato/ 2001; 117: 93-95.

14. Salama H, Salama M. The role of orthodontic extrusive remodeling in the enhancement of soft and hard tissue profiles before implant placement: a systematic approach to the management of extraction site defects. Int J Periodont Rest Dent 1993; 13: 312-333.

15. Darby I, Chen S T, Buser D. Ridge preservation techniques for implant therapy. Int J Oral Maxillofac Implants 2009; 24: 260-271.

16. Lindeboom J A, Tjiook Y, Kroon F H. Immediate placement of implants in periapical infected sites: a prospective randomized study in 50 patients. Oral Surg Oral Med Oral Pathol Oral Radiol Endod 2006; 101: 705-710.

17. Esposito M, Grusovin M G, Polyzos I P, Felice $P$, Worthington $\mathrm{HV}$. Interventions for replacing missing teeth: dental implants in fresh extraction sockets (immediate, immediate-delayed and delayed implants). Cochrane Database Syst Rev 2010; 9: CD005968.

18. Block M S. Techniques for grafting the extraction socket. In Block M S (ed) A colour atlas of dental implant surgery. 2nd ed. pp 189. Oxford: Elsevier, 2007.

19. Covani U, Bortolaia C, Barone A, Sbordone L Buccolingual crestal bone changes after immediate and delayed implant placement. J Periodonto/ 2004; 75: 1605-1612.

20. Paolantonio M, Dolci M, Scarano A et al. Immediate implantation in fresh extraction sockets. A controlled clinical and histological study in man. J Periodontol 2001; 72: 1560-1571.

21. Botticelli D, Berglundh $T$, Lindhe J. Hard-tissue alterations following immediate implant placement in extraction sites. J Clin Periodontol 2004; 31: 820-828.

22. Rosenquist B, Grenthe B. Immediate placement of implants into extraction sockets: implant survival. Int J Oral Maxillofac Implants 1996; 11: 205-209.

23. Cosyn J, Hooghe N, De Bruyn H. A systematic review of advanced recession following single immediate implant treatment. J Clin Periodonto/ 2012; 39: 582-589.

24. Chen S T, Wilson T G Jr, Hammerle C H. Immediate or early placement of implants following tooth extraction: review of biologic basis, clinical procedures, and outcomes. Int J Oral Maxillofac Implants 2004; 19: $12-25$. 
25. Block M S. Techniques for grafting the extraction socket. In Block M S (ed) A colour atlas of dental implant surgery. 2nd ed. pp 193. Oxford: Elsevier 2007.

26. Harris D, Horner K, Grondahl K, Jacobs R, Helmrot E et al. E A.O guidelines for the use of diagnostic imaging in implant dentistry 2011. A consensus workshop organized by the European Association for Osseointegration at the Medical University of Warsaw. Clin Oral Implant Res 2012; 23: 1243-1253.

27. Young M P, Worthington H V, Lloyd R E, Drucker D B, Sloan P, Carter D H. Bone collected during dental implant surgery: a clinical and histological study. Clin Oral Implants Res 2002; 13: 298-303.

28. Raghoebar G M, Batenburg R H, Vissink $A$

Reintsema H. Augmentation of localized defects of the anterior maxillary ridge with autogenous bone before insertion of implants. J Oral Maxillofac Surg 1996; 54: 1180-1185.

29. Joshi A. An investigation of post-operative morbidity following chin graft surgery. Br Dent J 2004; 196: $215-218$

30. Chesterman J, Patel M, Chan M, Carter L. Seven-year outcome data of autogenous block onlay bone grafts used to augment the alveolar ridge before implant rehabilitation. Implant Dent Today 2014; January edition: 7-10.

31. Jenson S S, Terheyden H. Bone augmentation procedures in localised defects in the alveolar ridge: Clinical results with different bone grafts and bonesubstitute materials. Int J Oral Maxillofacl Implants 2009; 24: 218-236.

32. Buser $D$, Bornstein MM, Weber HP, Grütter L, Schmid B, Belser UC. Early implant placement with simultaneous guided bone regeneration following single-tooth extraction in the esthetic zone: a crosssectional, retrospective study in 45 subjects with a 2- to 4-year follow-up. J Periodonto/ 2008; 79: 1773-1781.

33. Choquet $V$, Hermans $M$, Adriaenssens $P$, Daelemans P, Tarnow D P, Malevez C. Clinical and radiographic evaluation of the papilla level adjacent to singletooth dental implants. A retrospective study in the maxillary anterior region. J Periodontol 2001; 72: 1364-1371.

34. Buser D, Von Arx T. Surgical procedures in partially edentulous patients with ITI implants. Clin Oral Implants Res 2000; 11: 83-100.

35. Brito C, Tenenbaum H C, Wong B K, Schmitt C, Noqueira-Filho $G$. Is keratinized mucosa indispensable to maintain peri-implant health? A systematic review of the literature. J Biomed Mater Res B Appl Biomater 2014; 102: 643-650. 